\title{
Use of telemedicine-based care for the aging and elderly: promises and pitfalls
}

This article was published in the following Dove Press journal:

Smart Homecare Technology and TeleHealth

7 May 2015

Number of times this article has been viewed

\section{Maria Magdalena \\ Bujnowska-Fedak \\ Urszula Grata-Borkowska}

Department of Family Medicine, Wrocław Medical University,

Wrocław, Poland
Correspondence: Maria Magdalena Bujnowska-Fedak

Department of Family Medicine,

Wrocław Medical University,

Syrokomli I, 5I-I4I Wrocław, Poland

Tel +48 7I 3266876

Fax +48 7I 325 434।

Email mbujnowska@poczta.onet.pl
Abstract: Telemedicine-based care provides remote health and social care to maintain people's autonomy and increase their quality of life. The rapidly aging population has come with a significant increase in the prevalence of chronic diseases and their effects, and thus the need for increased care and welfare. The elderly have become one of the main target groups for telecare technologies. Smart home systems allow older adults to live in the environment of their choice and protect them against institutionalization or placement in a nursing home. It gives the elderly person a feeling of reassurance and safety, and appears to be one of the most promising approaches to facilitate independent living in a community-dwelling situation. Telecare solutions give a new opportunity for diagnosis, treatment, education, and rehabilitation, and make it possible to monitor patients with a number of chronic diseases. It also reduces socioeconomic disparity with regard to access to care and gives equal chances to patients from urban and rural areas. However, although telecare has undisputed benefits, it also has some limitations. Older people are often resistant to use of new technology, in particular acquiring the knowledge and skills necessary for use of electronic devices and computer systems. Further, privacy and security are important elements when building confidence in telemedicine systems. Leaking of sensitive information, such as health or test results, may have a negative and far-reaching impact on the personal and professional life of the patient. Telemedicine-based care should now be personalized for the needs, capabilities, and preferences of the elderly, with adaptation over time as care needs evolve. If technologies are introduced that are familiar, usable, desirable, and cost-effective, and able to be adapted to seniors' lives and plans, then telecare would become an integral part of the lives of the elderly in the near future, allowing them to function independently in a friendly home environment.

Keywords: home telecare, aging, elderly, benefits, barriers

\section{Introduction}

Telemedicine is the most modern form of provision of medical services, and is used in situations where the physician and patient are not in the same place. ${ }^{1,2}$ Using modern information and communication technology, telemedicine combines the needs of patients and technological progress, beyond the frontiers of traditional health care systems. In turn, telemedicine-based care (defined here as telecare) concentrates directly on users (patients), bringing remote health and social care to support the user in remaining independent, and avoids the exchange of information being solely between health professionals. ${ }^{3}$ Telecare includes technical devices and assistive technology as well as professional health care services to assist, monitor, and care for people from a distance. It includes a variety of services, such as communication, consultation, 
monitoring, diagnostics, and training to maintain autonomy and increase the quality of life of users. ${ }^{4}$

As the population ages and the prevalence of long-term conditions increases, telecare is increasingly being used to help elderly people maintain their independence and continue living in their own homes. ${ }^{3}$ Elderly individuals have become one of the main target groups for telecare technologies, with many devices available for people with chronic health conditions and for those with limited mobility or memory problems typical of advanced age. In this paper, the authors outline the growing phenomenon of our aging society and implementation of telecare in this age group. An overview of the main needs of the elderly that can be addressed by telecare is given, along with examples of various telecare programs currently underway throughout world. The authors also discuss the many benefits of successful telecare solutions, as well as barriers to development of telecare and the associated risks and pitfalls. Finally, we summarize the perceptions and attitudes of the elderly themselves toward telecare applications, along with trends in uptake and implications for the future.

\section{Demographics and the aging population}

Demographic trends indicate a rapidly aging population throughout the world, particularly in Europe. Many societies, especially in the more developed regions, now have aged populations that are larger than has ever been seen in the past. Between 2000 and 2050, the proportion of the world's population over 60 years of age will double from about $11 \%$ to $22 \%$. In absolute terms, the number of people aged 60 years or older is expected to increase from 605 million to 2 billion in the same period. The number of people aged over 80 years is growing particularly rapidly, and it is anticipated that this number will quadruple in the $2000-2050$ period. ${ }^{5}$ In Europe, the proportion of old people (over 65 years of age) is expected to increase from $18.2 \%$ in 2013 to $28.1 \%$ in 2050 . The European Commission also forecasts that the proportion of people over 80 years of age will increase from $5.1 \%$ in 2013 to $10.9 \%$ in $2050 .{ }^{6}$ Among the individual countries, those with the most aged populations are Italy and Germany, where $20.8 \%$ and $20.6 \%$ of the population, respectively, was aged 65 years or older in 2012. Many European countries, as well as Japan, have percentages nearly as high. ${ }^{7}$ In turn, in the USA, the population aged over 65 years accounts for slightly less at $14.5 \%$, but by 2030 , older adults will comprise about $20 \%$ of the population. ${ }^{8}$

Aging societies worldwide are a result of both longer life expectancy and declining fertility. Demographic projections assume that every other person born since the beginning of the 21 st century in countries such as Germany, Italy, France, the UK, the USA, Canada, and Japan will live to 100 years. ${ }^{9}$ The increase in life expectancy is mainly due to better public health measures, improvements in social and living conditions, advances in medical care, and growth of public health awareness. A marked reduction in mortality rates has also contributed to increased life expectancy statistics. ${ }^{7,10}$ Nowadays, the longest life expectancy is in Japan, where the mean life expectancy is 84.6 years ( 87 years for women and approximately 80 years for men), and in 2025 , the country is expected to have twice as many old people as children. ${ }^{10}$ In the USA, current life expectancy at birth is estimated at 79.6 years overall (77.1 years for males and 81.9 years for females). ${ }^{8}$

There is a distinct gap between rich and poor countries. A boy born in 2012 in a high-income country can expect to live to the age of around 76 years, which is 16 years longer than for a boy born in a low-income country (who has a life expectancy of 60 years). For girls, the difference is even wider; a gap of 19 years separates life expectancy in highincome (82 years) and low-income countries (63 years). ${ }^{10}$ On the other hand, according to the annual statistics report published by the World Health Organization, low-income countries have made the greatest progress, with an average increase in life expectancy of 9 years from 1990 to 2012. The country in which life expectancy has increased the most is Liberia, with a 20-year increase (from 42 years in 1990 to 62 years in 2012) followed by Ethiopia (from 45 years to 64 years), the Maldives (from 58 years to 77 years), and Cambodia (from 54 years to 72 years). ${ }^{10}$ The age structure of populations has also become older. The population in developing countries is still very young (eg, in 2014, children aged $<15$ years account for $41 \%$ of the population in Africa, with the elderly aged 65 years and older comprising $4 \%$ ), but the percentage of old people is growing rapidly. ${ }^{11}$ Over the next three decades, the population aged 60 years or over in the developing world is projected to increase at rates far surpassing 3\% per year, and numbers are expected to increase from 510 million in 2011 to 1.6 billion in 2050 and to 2.4 billion in $2100 .{ }^{12}$

\section{Characteristics of the aging population, and their health and social care needs}

There can be little doubt that changes in age distribution have complex health, social, and economic implications at the individual and community level. A rapidly aging population 
comes with a significant increase in the prevalence of chronic diseases and their effects, and thus the need for more care and welfare. Old people often have multiple comorbidities and are more likely to be on polypharmacy. The current reported proportion of the elderly having at least two concurrent chronic diseases ranges from $55 \%$ to $98 \%$, and the prevalence of elderly with multimorbidity is expected to increase, lead seniors to have permanent impairment of efficiency (functional decline), disability, and poor quality of life. ${ }^{13,14}$ Agedependent diseases ("off aging") that frequently occur during the process of aging include dementia (prevalence increases over thirty times at age 60-80 years), stroke, vascular complications of atherosclerosis, osteoarthritis, cancers, incontinence, osteoporosis, falls, fractures, and bedsores. ${ }^{15}$ These diseases result in physical and mental decline, resulting in a need for continuous supervision and intensive contact with health and social care centers.

An important and increasingly recognized pathology in the elderly is "frailty syndrome". Its name comes from the word "frail", meaning "weak" or "fragile". The development of frailty involves declines in energy production, energy utilization, and repair systems in the body, resulting in decreased function of a number of physiological systems. Frail older adults are at high risk for major adverse health outcomes, including increased susceptibility to acute diseases, falls, disability, institutionalization (eg, in a nursing home), hospitalization, and mortality. The American Cardiovascular Health study, conducted in a population of more than 5,000 elderly people, showed that $7 \%$ of people over 65 years of age and $30 \%$ of those aged 80 years or older fulfilled the diagnostic criteria for frailty syndrome. Women more often presented features typical for "frailty", and increased risk of death in its course was an independent factor regardless of whether such persons had chronic diseases or not. ${ }^{16}$ Multimorbidity and frailty frequently overlap and, although they should not be confused, they are interrelated. In particular, the presence of multiple diseases is recognized as a risk factor for frailty. ${ }^{17,18}$

The consequence of demographic aging is the existence of many single-dwelling elderly people in our communities. Older persons are increasingly being forced into singularization, ie, living in a single household, because of, for example, death of a spouse. In Canada, 2011 census data showed that about one quarter $(24.6 \%)$ of the population aged 65 years or over lived alone. ${ }^{19}$ Women are nearly twice as likely to live alone (31.5\% versus $16.0 \%$ for men). Use of traditional health services, whereby the patient attends a medical facility alone, becomes burdensome for many seniors, if not impossible, especially in a situation where they live alone and can rely only on themselves.

Associated with age is a significantly higher incidence of chronic disease, frailty, and disability, involving excessive expenditure of resources and high utilization of community services. ${ }^{13,20}$ In addition to a steady growth in demand for medical and social services, a proportional increase in funding has been observed. Statistics show that in the majority of well-developed countries, the expenditure incurred by the health care system for the diagnosis and treatment of patients suffering from chronic diseases every year is significantly increased. Five percent of patients with multiple chronic conditions are responsible for $50 \%$ of the costs in most health care systems. ${ }^{21}$ In the USA in 2010, those aged 65 years and older required expenditure of about $\$ 18,424$ per person on personal health care, being "about three times more than the average working-age adult and about five times more than the average child", in 2014 according to the Census Bureau. ${ }^{22,23}$ The cost of caring for elderly persons with chronic diseases is also predicted to grow substantially in the coming decades, and Alzheimer's care alone may exceed \$1 trillion annually. ${ }^{22}$

\section{Telecare and its use for elderly people}

Telemedicine-based care is intended to meet the specific needs and expectations of elderly people. Among the branches of telecare dedicated in particular to older people, the leaders are telecare systems based in the home, which usually provide three main services:

- safety and security monitoring, eg, gas sensors, and flood and fire detectors

- monitoring health parameters and vital signs, such as heart rate, blood pressure, body temperature, and glucose levels

- support via information and communication technology (Internet, telephone), eg, teleconsultations, short message service (SMS) reminders for appointments and prescribed medicines, as well as educational text messages. ${ }^{3}$

\section{Social care at home: alarm systems, detectors, sensors, smart homes}

Limitations in physical and mental efficiency with increasing age can lead to potentially hazardous situations for elderly people. It is therefore advisable to monitor their activities of daily living. Assisted and independent living technologies refer to solutions that help older people to prolong their independent life at home. ${ }^{24,25}$ Telecare systems used for this 
purpose include a wide range of devices, mainly various types of sensors. The easiest and most widespread device for this purpose is the alarm button. The system usually consists of three interacting components: a transmitter, ie, an alarm button, usually in the form of a bracelet or a pendant worn by the user, and used to call for help; a terminal, ie, a device equipped with a microphone and speaker, run by the transmitter from anywhere in the home and enabling a conversation with a call center operator; and a call center that reads the signal sent, and through the terminal situated in the home, enables call center staff to make contact with the charge. If necessary, the system makes appropriate intervention possible, which may involve notifying emergency services, family, or neighbors.

With the progressive miniaturization and cost reduction of global position system receivers, new versions of alarm buttons have appeared on the market, which in addition to the ability to call for help make it possible to monitor the whereabouts of the user. The user carries a device equipped with a global position system receiver. A caregiver via the website can locate his or her charge by seeing the monitored device on a map, or by sending an SMS from a mobile phone asking about the location. In response, the caregiver receives the last recorded location of the device via SMS, which facilitates finding a missing person. There is also the opportunity to designate a safe area, adapted to the needs of the localized person. When the charge is inside this area, we recognize that the person is safe. However, in the event that the safe area has been exceeded, the guardian is informed immediately about the event via SMS. ${ }^{26,27}$ Such solutions are especially intended for mentally disabled people, eg, patients with Alzheimer's disease or other types of dementia. The system undoubtedly alleviates the burden related to caregiving. Family members are reassured that the elderly person is being monitored for undesirable situations, and professional caregivers can be relieved of low-level monitoring tasks.

Alarm buttons can also function as one of the more sophisticated and complex systems, such as "smart homes". ${ }^{24}$ For this purpose, various sensors are distributed inside the apartment/house. Potentially risky situations can be monitored and managed. For example, a gas or smoke detector can alert the user or a caregiver to a problem, turning off the gas supply if a cooker is not lit, and a flood detector can report an overflowing sink or bath in the event that the user leaves a tap running. Motion sensors distributed in the house detect when there is no movement or movement in an unusual location, and personal motion sensors inform about the movement of the user within the house. Moreover, smart homes should support peace of mind in the home. Systems usually include automatic control of water temperature, stove and oven shutoff, lighting, door and window security, intruder alarm, and visitor identification. ${ }^{27,28}$ Besides security sensors, a home care system can use software services, eg, for communication (email, SMS, videoconferencing, and community television), allowing the user to stay in touch with family, friends, and caregivers.

To maintain health and quality of life and to manage diseases in the aging population, smart homes can also been equipped with medical health monitoring devices and e-health technology. When a health monitoring system is embedded in a smart home, older people can live at home while receiving medical support. Home-based technologies may be most effective if they also promote a healthy lifestyle. Frequently used applications are fall detectors and gait monitoring, observation of behavior and sleep patterns, adherence to medical treatment (eg, a talking pill box that reminds the elderly to take their medicines and notifies caregivers of omissions), ${ }^{28}$ checking of caloric intake, and monitoring vital signs..$^{24,25}$

\section{Health care at home: monitoring health parameters and vital signs}

The telemedicine-based home provides integrated and comprehensive supervision of chronically ill patients and elderly by using information and communication technology tools in a friendly home environment (Figure 1). By using the telecare system, the patient is monitored in a holistic way. Supervision includes both remote contact between the patient, doctor, nurse, or other health professional in the form of teleconsultation/videoconferencing, as well as monitoring of vital signs (heart rate, electrocardiogram, blood pressure, temperature, blood glucose, oxygen saturation, and weight), falls, syncope, and other potentially dangerous situations. The aim is for the older person, if temporarily or permanently disabled, to remain safely in the home environment under constant medical supervision. ${ }^{29}$ The patient has access to their general practitioner, as well as specialists, nurses, and other health professionals, regardless of their place of residence, and the necessary tests can be done at any time of day or night. Direct and rapid access to medical services and urgent consultation with a doctor without having to leave home and waiting in long queues for a visit make telemedicine modules an extremely convenient solution for seniors and disabled people. Patients with chronic diseases and those undergoing 


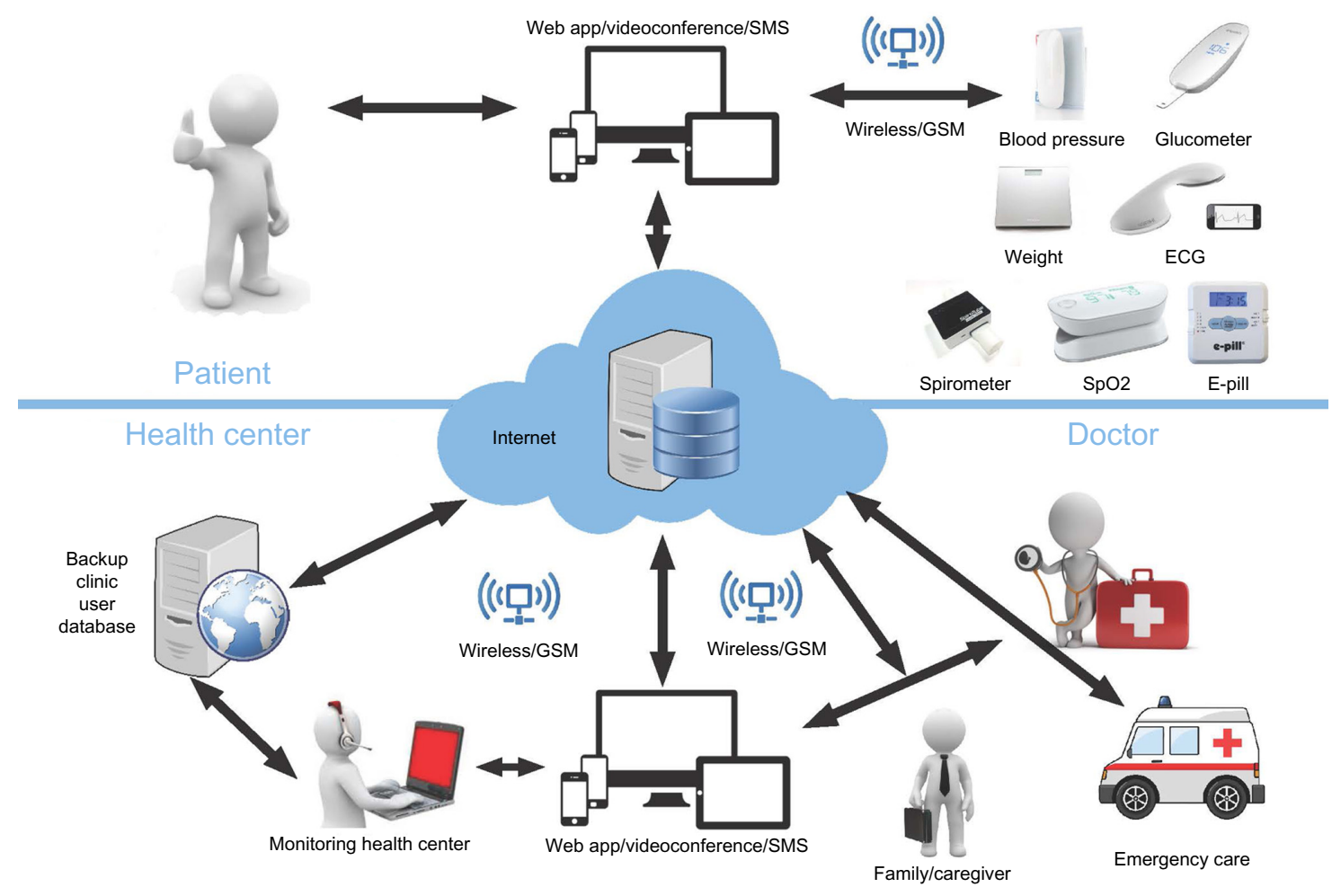

Figure I Scheme of a home telecare system.

Abbreviations: app, application; ECG, electrocardiogram; GSM, Global System for Mobile communications; SMS, short message service; SpO2, oxygen saturation.

long-term convalescence who are receiving home telecare are usually discharged earlier from hospital, and the amount and frequency of emergency calls and hospital readmissions also decreases considerably, especially in patients over 65 years of age. ${ }^{30,31}$

Through use of Internet networks and telecommunication, telesystems can also enable the elderly to participate more fully in society, by reducing their sense of danger, loneliness, and isolation. An audiovisual interaction with a doctor or nurse gives the patient a sense of direct contact with the health care professional, despite physical remoteness. One such example is in the Nordic countries, where the primary platform for telemedicine communication is usually interactive digital television. ${ }^{25}$

The home telecare system can be very helpful for seniors living in rural areas. ${ }^{32}$ In addition to the usual challenges of chronic diseases and functional decline, the rural elderly often face geographic isolation. Many small but dispersed rural communities may have only two or three physicians and a handful of nurse practitioners, all of whom have full caseloads. It is often the case that rural health care patients in need of specialist attention must travel to larger urban areas or make an appointment with a visiting specialist. Typically, the appointment is weeks or months in the future. Thanks to telecare technologies, these patients can receive specialty care sooner and may remain in their own community. Remote health monitoring and management, regular online contact with health professionals, and substantial reduction of the need to travel long distances seem exceptionally promising in this setting. ${ }^{33}$

\section{Selective review of telemedicine- based care in the elderly}

The concept of smart homes allows older adults to live in the environment of their choice and protect them against institutionalization or nursing home placement for as long as possible. Use of these technologies in a home setting is still under development, but this method appears to be one of the most promising approaches to facilitate independent living for older community-dwelling adults when use of the Internet and mobile phones becomes universal. The system gives the elderly a feeling of reassurance and safety, and allows them to stay in a friendly home environment.

The required functionalities of buildings for the needs of patients may already be taken into account at the design stage. However, they are still very expensive solutions accessible only to the wealthy. The clear leader in this type of technology is the USA, where the first prototypes of smart homes 
have been created to ensure the safety and independent functioning and quality of life of their occupants, eg, the prototype smart medical home at the University of Rochester's Center for Future Health and the real functioning smart home at the Vinson Hall Retirement Community in Missouri, which serves retired US officers and their families. ${ }^{24}$ Examples of companies providing such services in the European market are Tunstall and Tynetec. ${ }^{27,34}$ The concept of smart homes is also being developed as part of MATCH (Mobilising Advanced Technologies for Care at Home), a research project run by the universities of Stirling, Dundee, Edinburgh, and Glasgow in Scotland. ${ }^{35}$ The project is focused on technologies for care at home to maintain the independence of elderly people receiving social and health care, improve their quality of life, enhance the care they receive at home, and ease the burden on their caregivers.

In Europe, the USA, and worldwide, university centers, governments, local administrative bodies, and information technology corporations such Cisco, Intel, IBM, and Microsoft are developing an array of programs aimed at development and implementation of services in the field of telecare intended primarily for the elderly. Examples of such activities include the German government research program "Ageing Related Support Systems for Healthy and Independent Living" using the SOPHIA platform. ${ }^{36}$ The program emphasizes the exploitation of modern technology to enable older people who are in need of support to continue to live in their own homes. In addition to a basic SOPHIA service package that meets a wide spectrum of personal needs, a security package is available that includes a personal alarm service utilizing an intelligent wrist band and, if required, various sensors placed in the client's home (eg, gas and fire sensors), as well as a contact package enabling video telephone contact established via an ordinary television set with the service center or any other party (eg, family member or friend). Another example is the multifaceted UK program known as DALLAS (Delivering Assisted Living Lifestyles at Scale), which is evaluating services and technologies for improving the quality of life and supporting the independent existence of the elderly and disabled in their home environment, ${ }^{37}$ along with a number of research programs conducted by the Veterans Administration in the USA. ${ }^{24,38}$ Japan excels in such systems, with the use of high-tech robots to provide the necessary services for older people in terms of their basic activities of daily living (eg, bathing, feeding, and carrying). ${ }^{39,40}$

Telecare solutions make it possible to monitor patients with a chronic disease, such as heart failure, hypertension, diabetes, asthma, chronic obstructive pulmonary disease, or stroke. ${ }^{4,29,41,42}$ The goal of telemonitoring is to identify and manage disorders, functional decline, and other key changes in medical status before the person requires acute care in the emergency department or hospital, or long-term care in a nursing facility. Home telemonitoring of chronic disease seems to be a promising approach to patient management that produces accurate and reliable data, empowers patients, influences their attitudes and behaviors, and potentially improves their medical conditions. ${ }^{31,41}$ A systematic review of the nature and magnitude of outcomes associated with telemonitoring for four types of chronic illness, ie, pulmonary disease, diabetes, hypertension, and cardiovascular disease, conducted by Parè et $\mathrm{al}^{41}$ suggests that patients comply with telemonitoring programs and use of technology regardless of their nationality, socioeconomic status, or age. In a randomized controlled study of patients with complex heart failure, chronic lung disease, and/or diabetes mellitus, Noel et $\mathrm{al}^{43}$ reported a reduction in bed days and emergency department visits when patients used a home-based telemonitoring system capable of measuring vital signs, blood glucose levels, auscultation of heart and lungs, three-lead electrocardiography, pulse oximetry, and pain assessment. In turn, in a similar randomized controlled trial in patients with chronic obstructive lung disease, chronic heart failure, or a chronic wound, fewer patients were rehospitalized in the telemonitoring group, which used videoconferencing and physiological monitoring of vital signs, spirometry, and pulse oximetry. ${ }^{44}$

The results of many demonstration projects and pilot studies evaluating the effectiveness of telemonitoring have been favorable. ${ }^{3,4,45}$ Telemonitoring can identify worsening heart failure, and home telemonitoring in a typical elderly population of heart failure patients produced a similar outcome to "usual" specialist care, also decreasing clinic and emergency room visits and unplanned rehospitalizations for heart failure. ${ }^{46}$ Prato et $\mathrm{a}^{47}$ have devised a system for patients with type 2 diabetes initiating insulin therapy. Blood glucose can be monitored with the help of a device that measures blood glucose and transmits levels by telephone from the patient's home to a centralized server. The results are made available to a health care professional who can then transmit information (eg, dose titration) to the centralized server. Information is then returned to the patient by telephone. The system proved to be as effective in the control of diabetes as conventional self-monitored blood glucose programs. As confirmed by numerous scientific reports, telemedicine systems for monitoring diabetes could improve glycemic 
control, increase awareness of the nature and consequences of the disease, have an important educational function, and improve quality of life by providing closer cooperation and mutual trust between the patient and doctor. ${ }^{48-51}$

Since the age group most frequently requiring comprehensive rehabilitation includes people over 60 years of age, they are the main recipients of home telerehabilitation programs. Currently, besides cardiology, rehabilitation at a distance is also used in orthopedics, as well as in neurology and psychiatry. In its simplest form, the senior can play movies/videos at home with exercises chosen by the therapist. In more advanced systems, the therapist tracks exercises performed by the patient online. This innovative model of rehabilitation is offered by Habilis Europe. ${ }^{52}$ The concept is based on a flexible and low-cost platform suitable for implementing an expandable set of telerehabilitation services across the whole European Union. The Habilis platform can deliver this therapy to people who cannot travel to a clinic because of disability and to circumvent travel-related problems. It also allows experts in rehabilitation to engage in a clinical consultation from a distance. Using the Habilis program, patients with physical, neurological, or cognitive impairment can be rehabilitated at home or near their home at telerehabilitation points spread across their territory and linked to clinical centers.

There is growing interest among physicians and rehabilitants in the commercial use of video game consoles like Nintendo Wii, PlayStation Move, and Kinect motion sensors together with appropriate software as therapeutic tools that can be used as home rehabilitation systems, mainly due to their low cost, the portable nature of the devices, and their ease of use. One such example is the Rehab@home system, which uses the Wii balance platform for home-based rehabilitation of patients with neurological disorders of a motor nature. ${ }^{53}$ As reported by several authors, home telerehabilitation using video game consoles has the desired therapeutic effects $^{53-55}$ and is positively received by patients, who feel more engaged and motivated to exercise, and the entire rehabilitation program is considered to be enjoyable and to improve their quality of life..$^{53,56}$

While home use devices are often sensors, detectors or monitoring systems that are permanently installed in the home, mobile devices can be carried around and used at any location. Mobile health information technology (m-health) is becoming more and more common around the world. Currently, there are over 3.5 billion mobile telephones in use across the globe; this figure is set to double in the next decade. ${ }^{57}$ In the USA, according to the Pew Research Center, ${ }^{58}$
$59 \%$ of people aged 65 years or older go online, and $77 \%$ of seniors use a mobile telephone. M-health typically refers to portable devices with the ability to create, store, retrieve, and transmit data in real time between end-users for the purpose of improving patient safety and quality of care. ${ }^{57}$ Mobile devices can be helpful for transmitting health parameters and vital information, and can be used for ongoing needs such as education and training. ${ }^{59}$ Mobile applications are widely used, primarily in the management of chronic diseases such as diabetes and hypertension. ${ }^{59,60}$

\section{Trends in uptake and implementation Benefits}

Telemedicine-based care offers many benefits for elderly people. Seniors who are users of e-health services can stay in their familiar home environment where they feel safe and comfortable. The awareness of being under constant monitoring has a positive impact on their sense of security and quality of life. ${ }^{51,61,62}$ Chou et al ${ }^{61}$ found that elderly persons with better social welfare and health status who used their telecare program frequently had better quality of life and accepted use of technology. Their results also indicated that elderly individuals who perceived telecare as useful in solving health problems and were willing to use it had a better perception of their quality of life, especially with regard to their interpersonal relationships and living environment. In turn, in a study concerning elderly recipients of social care conducted by Hirani et al, ${ }^{62}$ home-based telecare contributed to amelioration of health-related quality of life over a 12-month period. Telecare did not transform the lives of its users, but it did afford small benefits with regard to psychological and quality of life outcomes relative to elderly individuals who received usual care only.

At the same time, telecare allows the elderly to keep their independence and continue living in their own homes. With reduced mobility, simple and rapid online contact between the older person and health facility/health care professionals becomes particularly important, saving time on commuting and speeding up the diagnosis, minimizing duplication of diagnostic tests and clinical services, and enabling rational triaging of seniors. ${ }^{63}$ Telemonitoring and telerehabilitation help to reduce the number of hospitalizations and shorten their duration by providing some health care services in the patient's home, and the chronically ill patient can benefit by minimizing the number of follow-up visits needed at the health center. ${ }^{3,24,25,63}$ Thanks to telecare systems using e-health services, an elderly housebound person can register online 
for an appointment with the doctor, pick up a reminder of an upcoming deadline for a medical consultation, receive simple remote medical recommendations/test results (via SMS or email), and obtain ongoing prescription drugs directly from the pharmacy of their choice. ${ }^{64,65}$

The undeniable advantage is also the involvement of seniors in the process of treatment and rehabilitation and improvement of their health awareness. Patients who do well in a telecare program may not need to come in for their next regularly scheduled in-person visit. Telecare promotes greater engagement by letting patients help to design and choose which tools they will use and how they will use them. ${ }^{66}$ In the telecare system, patients can become active participants in their own care, not just passive recipients of health services. Using applications and home medical devices, they can track their conditions and send in their data and measurements for review. Patients who are not doing well can be scheduled for a telecare session or a regular visit before their condition worsens. They become equal partners with their doctors, being able to make independent decisions about their health and be aware of the consequences. ${ }^{67,68}$

Telemedicine-based care forms proactive healthy behaviors. Telemonitoring can detect pathological symptoms and abnormal test results earlier than during/before a routine medical visit or investigation in an emergency situation, thus allowing appropriate preventive measures to be taken early. ${ }^{24}$ Telemonitoring also plays an important educational role. Patients who are aware of their state of health often start to learn more about their condition and how to self-manage it. They know their bodies better and are more willing to take action to change undesirable habits and lead a more healthy lifestyle. ${ }^{24,63}$

Telecare decreases uneven distribution of quality of care and reduces socioeconomic and geographic disparities in access to care. One of the key attributes of telemedicine systems is electronic connectivity, which transcends time and distance barriers. With telecare technologies, elderly people have ready access to a series of geographically and functionality disparate health providers without having to travel to distant places and at times that are convenient for both the patient and the health care professional. Physicians in various practice locations can have ready access to efficient tools for clinical decision-making (eg, to expert colleagues at tertiary care centers) and to evidence-based medicine. At the same time, patients can receive an appropriate level of care nearest their homes, which in the case of older people with chronic disease/disability is a matter of particular importance and determines their quality of life and care. ${ }^{63,69}$
Finally, it should be borne in mind that telecare can support patients with severe mental and/or physical disability and their families/caregivers. ${ }^{24,70} \mathrm{~A}$ disoriented, fearful, suspicious patient with progressive dementia or the person who has had a stroke and is not able to perform even basic activities of daily living (such as dressing, eating, moving, bathing) losses their autonomy and becomes totally dependent on other people. In the USA, approximately 44 million individuals serve as informal and unpaid caregivers and provide $80 \%$ of the care for older adults. ${ }^{71}$ Many smart homes with monitoring systems include caregiver components. Smart home technology allows care recipients to be monitored within their home environment, while caregivers are able to receive health information that can be used to prevent or manage medical conditions. The ability to obtain help in times of distress can reduce worry and stress for both caregivers and older adults, and may increase caregiver satisfaction. ${ }^{24}$ The literature reveals that caregivers endure physical and mental burdens. With telecare solutions, nurses can provide supportive care to caregivers in their homes. Such support seems to help caregivers cope with their own physical and emotional problems. ${ }^{70}$

Favorable economic balance is strong motivation for the development of telecare systems. Approximately $75 \%-80 \%$ of health costs are attributable to chronic disease, a large percentage of which is preventable, but only when action is taken long before onset of the disease. ${ }^{63,72}$ Although evidence-based medicine shows no clear financial advantage of the telemedicine system over the traditional health care system for chronically ill patients, the vast majority of scientific publications indicates the economic benefits of use of telecare solutions. ${ }^{44,73-76}$ According to Paré et al, ${ }^{73}$ a 6-month home telecare program for patients with chronic obstructive pulmonary disease showed a significantly lower number of hospitalizations and nursing home visits among telemonitored patients and generated savings of $\$ 355$ per patient compared with the control group. On the other hand, in the study by Biermann et al, ${ }^{74}$ cost analysis showed savings of $€ 650$ per patient per year using a telecare system for patients with diabetes. In turn, Finkelstein et $\mathrm{al}^{44}$ found that virtual visits using videoconferencing technology between a skilled home health care nurse and chronically ill patients can be successfully implemented at a lower cost than traditional skilled face-to-face home health care visits.

As is well known, the patient's stay in hospital is one of the most cost-intensive medical procedures burdening the health care system. According to a report prepared by the German Kaufmännische Krankenkasse in Hannover, telecare reduced hospital stays for patients with heart failure 
by around $50 \%$, and the total cost of treatment was lower by nearly $€ 7,000$ per patient compared with a group of patients without telemedicine supervision..$^{72}$ In turn, in the multidimensional analysis conducted by Verhoeven et al, ${ }^{75}$ who reviewed telecare systems in patients with diabetes, most of the reported improvements concerned satisfaction with technology (26/39 studies), improved metabolic control (21/39), and cost reductions (16/39). These financial benefits were also reported by Callan and O'Shea, ${ }^{76}$ who analyzed the different telecare programs used to support older people who continue living at home. While all telecare programs generated some economic value, telecare that emphasized the family unit provided much stronger support than telecare used to support only physical or cognitive care needs.

At the same time, a large clinical trial known as IDEATel, performed in medically underserved areas of New York State, including a 6-year follow-up in patients with diabetes, showed that the cost of implementing the telemedicine intervention was high, ranging from $71 \%$ to $116 \%$ more for the home telecare group than for the control group monitored within the traditional health care system. ${ }^{77,78}$ However, the extensiveness and the complexity of the system, as well as difficulties in its use reported by the consortium and the expensive sets of sensors and hardware installed in participants' homes certainly contributed to this result. It should also be assumed that the high costs of the telemedicine group could be related to the fact that the system was implemented in a medically underserved group of patients, with low social and intellectual status, thus not being representative for the entire group of patients with diabetes.

\section{Barriers}

Telecare brings undisputed benefits, but it needs to be realized that it also has limitations (Table 1), some of which lie in the seniors themselves. Older people are often resistant to use of new technologies. While computers and the Internet have become indispensable technologies, seniors show more difficulty in using them than younger people. A Nielsen Norman Group study, assessing computer use in different age groups, found that a group of users over 65 years had a success rate of just $53 \%$ in completing a series of assigned tasks (such as finding information and making a purchase online), compared with a $78 \%$ success rate for a group of younger users. The elderly also made an average of 3.7 errors on each assigned task, compared with 0.6 errors in the younger group. ${ }^{79}$ The tendency of seniors to avoid computers and the Internet offers an important explanation as to why this group of people may have a lower rate of acceptance of broadband-enabled
Table I Benefits and barriers for implementing telecare in the elderly

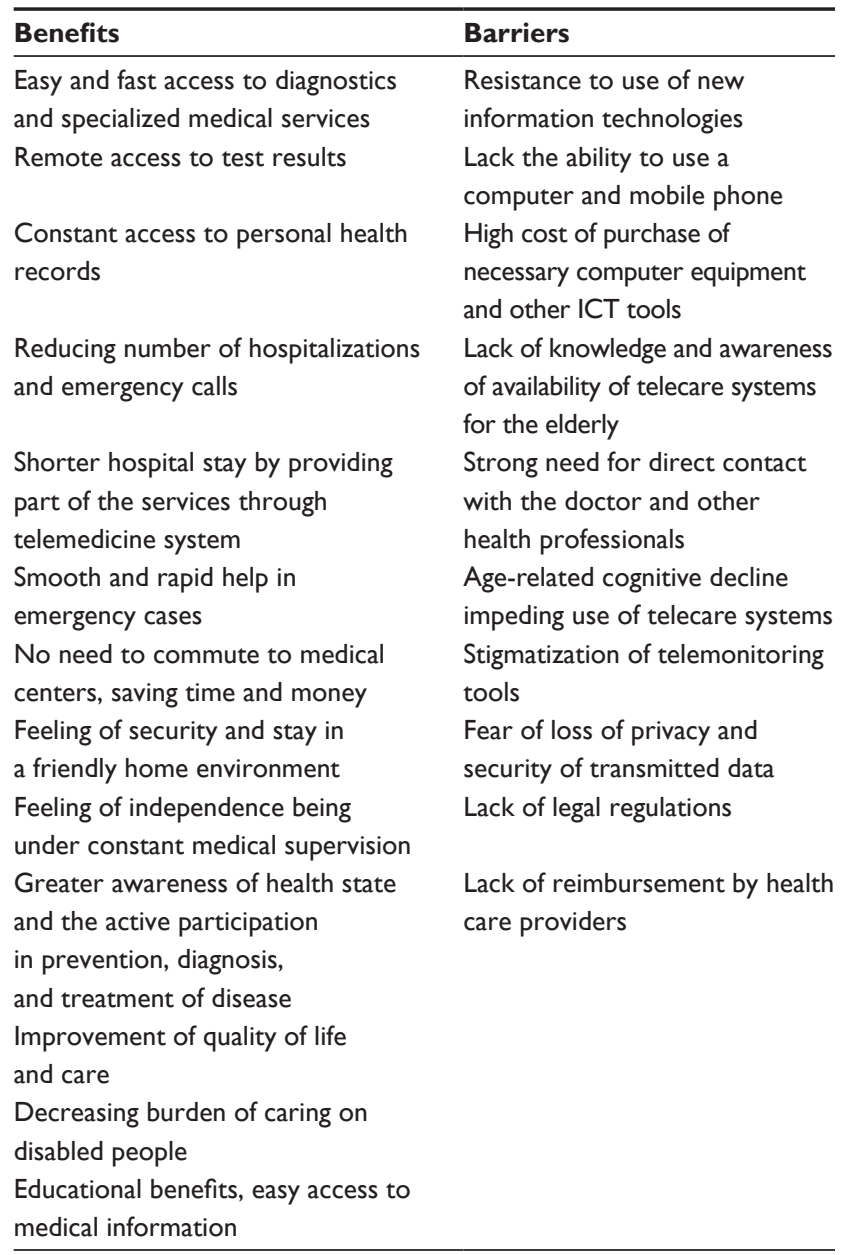

Abbreviation: ICT, information and communication technology.

telecare applications. The service is a novelty for many senior citizens, who are typically slow to adopt new technologies in the first place.$^{80}$ Another problem is the age-related impairment of cognitive and motor function (eg, vision impairment, hearing impairment, short memory loss, physical disability), and thus poorer absorption of new information and difficulty in adapting to a changing environment and assimilation of new forms of behavior. ${ }^{81}$ For example, severe mental and/or physical disability, eg, Alzheimer's disease, entirely deprives seniors of the opportunity to become active participants in the telecare system.

Another characteristic feature of seniors is a strong need to establish a direct face-to-face relationship with the doctor. Older people usually prefer personal contact with health professionals, which means that telemedicine-based services performed from a distance are often not perceived as relevant to them. In a study of the elderly aged 60 years and over performed by Bujnowska-Fedak and Mastalerz-Migas, ${ }^{82}$ $61 \%$ of seniors reported a strong preference to have direct 
contact with health professionals, and that this was the main reason for not approaching their family physician, specialist, or nurses over the Internet. Elimination of face-to-face care may create a perception of reduced social interaction in the older person's life. Older patients' resistance to telemedicine may arise because they feel that the new technology will negatively affect their social and personal contacts. The personal need for social interaction may be strong enough for older patients to consider refusing a technology that will ultimately improve their health and day to day life. ${ }^{80}$ In a study concerning patients' perceptions regarding home telecare conducted by Agrell et al, ${ }^{83}$ some interviewees reported a reduced amount of time spent "socializing" with nurses as compared with in-person visits and concerns about the ability of the system to approximate the social stimulation of in-person nursing visits. Older patients' fear of losing closely held personal relationships can also induce depression, causing further rejection of new health care monitoring technologies. Restricted activity (disability, multimorbidity) that does not allow the patient to move freely can also lead to depression because it means reduced social interaction, a reduced sense of impact and value as a person, and increased dependence in order to get through the day, even if the dependence is on technology. ${ }^{80,84}$

Finances are the next barrier. Pensioners, usually those who are indigent, fear the high costs of purchasing computer equipment or other electronic devices. Despite the health benefits and long-term cost savings made possible by telecare services, older people are often unwilling to invest in home health care monitoring systems. ${ }^{80}$ Most of them rely on a third party, usually government or employer health insurance, to pay for their health care and rarely make outof-pocket health purchases. Patients also rarely make preventative health care purchases, which further renders home health care monitoring systems an unattractive investment. ${ }^{85}$ Access to a telecommunication/computer network can be also limited, especially in developing countries. Telecare solutions require an appropriate information and communication infrastructure. Currently in Africa, only $11 \%$ of households have Internet access at home, 19\% of people use the Internet, and fixed broadband penetration is $0.4 \%{ }^{86}$ Internet penetration in Africa is half that of Asia and the Pacific, and is the lowest of any developing world region. In poor communities, people are mostly computer illiterate and few of the over 2,000 African languages are available on the Web. In rural areas, where telecare is needed the most by the poorest of the poor, it is least likely to be provided because of inadequate infrastructure and high connectivity costs. In addition, limited awareness of telemedicine-based care does not only concern patients and their communities but also health care workers, and there is often a lack of government will. ${ }^{87}$

Privacy and security are important elements in building confidence in telecare solutions. During data collection and processing, especially those relating to health, it is therefore necessary to ensure the right to privacy and protection of personal data. As with any other type of data transmission, there are risks involved in telemedicine-based care. Leaks of sensitive information, such as a medical condition or test results, may have a negative and far-reaching impact on the personal and professional life of the patient. In addition, patient data are valuable marketing tools, even for insurance and pharmaceutical companies. Concerns have been also raised about the ethics of monitoring older people's behavior in the privacy of their own homes and regarding the difficulty of ensuring that consent to be monitored by information and communication technology is genuinely "informed" when the recipient of the technology is frail or confused. ${ }^{69,88}$ Privacy and security are central personal fears for older adults. Many attitudes and perceptions of patients are centered on the potential privacy issues that arise with the improved range and resolution of data (such as video streaming and still images) and the improved technology that enables a person's location and activity to be tracked. ${ }^{89}$ Effective remote health care consultations may be avoided because older patients have concerns about the confidentiality of their personal information in "virtual" consultations. A Pew Internet survey ${ }^{90}$ showed that $61 \%$ of respondents aged 65 years or older were "very concerned" about businesses and people they did not know obtaining personal information about themselves or their families, compared with $46 \%$ of Americans aged 18-29 years. Older adults wish to have greater reassurance that their personal information is concealed from outsiders. They would rather be confident that their health information is secure than have better health care. Privacy safeguards in home health care monitoring may be necessary for full acceptance of telecare by seniors. ${ }^{80}$

Another barrier identified by researchers that older patients may have to overcome is the fear and stigma associated with using monitoring devices. Elderly people may refuse to wear a health monitor, especially in public, because they fear they will be perceived as old and weak. For example, many seniors do not use pendant alarms as they are seen as a sign of getting old or a "cry for help". ${ }^{25}$ The compromise between social acceptance, vanity, personal needs, appraisal about aging, and other issues may play a pivotal role in tak- 
ing the decision to join the telecare system. Older patients may choose not to benefit from health monitoring as they believe that monitoring devices signal their diminishing health to others. ${ }^{80}$

Finally, despite strong scientific evidence of the efficiency of remote health monitoring in improving care for older people, there are still some studies that do not confirm the benefits and trigger anxiety. A study by Takahashi et $\mathrm{al}^{91}$ examining telemonitoring in frail elderly patients with a mixture of chronic diseases yielded disturbing results. Although patients reported high satisfaction and a sense of safety, telemonitoring failed to reduce hospital admissions and emergency department visits. Surprisingly, telemonitoring resulted in a fourfold increase in mortality risk over 12 months. Mortality for the telemonitored group was $14.7 \%$ compared with 3.9\% for the usual care group. This suggests that telemonitoring in frail elderly patients is hazardous and may do more harm than good. However, one can question the validity of this conclusion. The researchers were unable to explain the differences between the groups, but suggested it could be because of an increased number of interventions and tests in the telemonitoring group. Despite randomization, it was also not clear if both groups were really comparable with regard to their baseline mortality risk. ${ }^{92}$

\section{Patient acceptance and satisfaction: implications for the future}

A key element in the development of telecare systems for the elderly is widespread acceptance by older people themselves. ${ }^{25,69,93}$ Until now, telecare solutions have tended to be closed, single-purpose, inflexible, and specialized. The needs of seniors vary widely and can change over time. It is therefore necessary to personalize and customize telecare systems for a variety of abilities of seniors, addressing their evolving care needs in a flexible and adaptable way, each time taking into account their impaired sensory (eg, sight, hearing), motor, and/or mental function. ${ }^{69}$ All elderly persons must be familiar with the operation and aware of the benefits of telecare systems before becoming users. Further, perceived ease of use of home telecare is a significant predictor of compliance with telecare on the part of older people and their caregivers. If the system is given a chance to fit into the everyday lifestyle of the elderly, giving them a sense of security and at the same time allowing them to lead a more independent life, its acceptance will increase significantly. ${ }^{25,69,89}$

A study performed by Bujnowska and Pirogowicz ${ }^{64}$ showed that approximately $41 \%$ of the elderly had a favorable attitude toward e-health services and were willing to use it if/when offered an opportunity to do so. A substantial majority $(84 \%)$ of supporters expressed a desire to receive simple medical recommendations via mobile phone or a computer, although significant majorities (61\% and 60\%, respectively) wanted to receive the results of tests by email or SMS reminders for scheduled visits or prescribed medications. Slightly less than half (47\%) of e-health supporters would request appointments online. Among the more important factors associated with support of e-health services were urban residence, higher education, and normal cognitive function, as well as having a computer, Internet access, or a mobile telephone. Similar results were found by Duplaga ${ }^{65}$ assessing the acceptance of the use of e-health applications by patients suffering from chronic respiratory conditions. In that study, respondents revealed the highest acceptance of e-health solutions allowing them to book appointments with physicians, access laboratory test results, view educational resources, and renew prescriptions. Acceptance of the most popular e-health applications depended on the duration of disease, the respondent's age and education, and their use of computers and the Internet.

Besides acceptance and a positive attitude, satisfaction using telecare solutions stimulates further implementation and development of telemedicine systems. As was reported by Chae et $\mathrm{al}^{94}$ in a study of home health services for elderly patients, telecare was effective in terms of reducing the number of clinic visits and achieving patient satisfaction. Seventy-two percent of patients were satisfied with telecare, and older people in their homes $(82 \%)$ were more satisfied than elderly in nursing homes (50\%). Of several types of services provided, remote medical consultation (100\%) was the most highly satisfactory service, followed by physical therapy (83.3\%). Furthermore, another study assessing patients' perceptions regarding home telecare revealed that most had either a neutral $(60 \%)$ or positive $(33 \%)$ outlook regarding home telecare before their enrollment. Following enrollment, all were either very satisfied $(67 \%)$ or somewhat satisfied (33\%) with the services they had received. Ninety-three percent were willing to receive home telecare services in the future, and all would recommend home telecare to friends or family members. ${ }^{83}$ The level of trust in telecare on the part of family members of older people using the service is also extremely important. Family trust may be an influential factor in deciding whether to use such services. The study conducted by Tsai et $\mathrm{al}^{95}$ showed that older Taiwanese people who were satisfied with telecare services scored an average of 4.25 (on a 5-point Likert scale) regarding overall service quality. Both older peoples' 
satisfaction and families' trust were influential in decided whether to continue to use telecare services.

\section{Summary}

The development of telemedicine-based care is gaining momentum. With advances in technology, it is now possible to implement solutions that until recently seemed to be a distant vision of the future. In addition to the rapidly expanding technology and computer science, demography and economics are additional factors driving the development of telecare. A generally aging population has become increasingly involved in the health care system while generating increasing costs.

Innovative telecare solutions are increasingly finding their place in the care of older patients and undoubtedly bringing a number of benefits. Telecare provides new opportunities for education, prevention, diagnosis, treatment, and rehabilitation, and improves quality of life for older patients with chronic diseases. It reduces socioeconomic disparities in access to care and provides equal opportunities for patients from urban and rural areas.

In well-developed countries, there has been a significant move in recent years from passive monitoring to more active use of telecare technologies that allow and encourage direct interaction. The increasing shift in the balance of care empowers patients to manage their own health and wellbeing. ${ }^{25}$ They become equal partners with their doctors, and are able to make independent decisions about their health and be aware of consequences. They can be responsible for their health condition, adequate nutrition, regular physical activity, and other pro-healthy behaviors. The change is due in part to older adults being more computer-knowledgeable and having a better economic position. Residents in the USA, Japan, the UK, and other well-developed countries want good quality of life as they age. They work hard throughout their life and can then lead a comfortable, prosperous, and healthy life in their old age. ${ }^{96}$

Mobile health information technology is spreading very rapidly and seems to be our future. Mobile devices can be taken by the elderly everywhere and used at any location. It is likely that the smart phone will become the preferred solution for collecting and analyzing health and lifestyle data, and for providing care support. Body sensor networks are also a promising development for home and mobile use. In future, sensors may take the form of implants that monitor vital signs and everyday activity. ${ }^{25,57,97}$

Telemedicine-based care should now be personalized for the needs, capabilities, and preferences of the elderly, with adaptation over time as care needs evolve. Telecare solutions must fit into homes and lifestyles and not be stigmatizing. Health and wellbeing are personal and valuable enough that many people are reluctant to change their usual activities and care plan. They hesitate to accept new technology in their homes if they are not aware of the benefits or equipped with enough knowledge and skills to exploit technology. ${ }^{89}$ Continuous education of the elderly in this area and training for ease of use of telecare appear undoubtedly very important. ${ }^{98}$ Many seniors, despite the increasingly widespread use of computers and mobile telephones, are not even aware of the possibilities that telemedicine offers them. In this situation, promotion and education activities and regular informatics trainings addressed to the elderly, eg, free courses in computer and Internet use, information and educational meetings, and third age universities, are of particular significance. If technologies are introduced that are familiar, usable, desirable, cost-effective, and fit into seniors' lives and plans, then telecare will soon become an integral part of life for the elderly, allowing them to function independently in a friendly home environment.

\section{Disclosure}

The authors report no conflicts of interest in this work.

\section{References}

1. Sosa-Ludicissa M, Wootton R, Olga Ferrer-Roca O. History of telemedicine. In: Ferrer-Roca O, Sosa-Ludicissa M, editors. Handbook of Telemedicine. Amsterdam, The Netherlands: IOS Press; 1998.

2. Bashshur RL, Reardon TG, Shannon GW. Telemedicine: a new health care delivery system. Annu Rev Public Health. 2000;21:613-637.

3. Barlow J, Singh D, Bayer S, Curry R. A systematic review of the benefits of home telecare for frail elderly people and those with long-term conditions. J Telemed Telecare. 2007;13:172-179.

4. PACITA Project. EU stakeholder involvement on ageing society. Telecare technology for an ageing society in Europe. Current state and future developments. Available from: http://wp6.pacitaproject.eu/ wp-content/uploads/2014/02/Telecare-description-web.pdf. Accessed December 29, 2014.

5. World Health Organization. Ageing and life course. Ten facts on ageing and the life course. Available from: http://www.who.int/features/ factfiles/ageing/ageing_facts/en/index.html. Accessed December 15, 2014.

6. European Commission. Population structure by major age groups, EU-28, 2013-80. Eurostat, the Statistical Office of the European Union, May 2014. Available from: http://ec.europa.eu/eurostat/statistics-explained/ index.php/File:Population_structure_by_major_age_groups,_EU-28, 2013\%E2\%80\%9380_(1)_(\%25_of_total_population)_YB14.png. Accessed December 15, 2014.

7. European Commission. Population structure and ageing. Eurostat, the Statistical Office of the European Union, May 2014. Available from: http://ec.europa.eu/eurostat/statistics-explained/index.php/Population_ structure_and_ageing. Accessed December 15, 2014.

8. Index Mundi. United States Demographics Profile 2014. Available from: http://www.indexmundi.com/united_states/demographics_profile.html. Accessed December 15, 2014.

9. Christensen K, Doblhammer G, Rau R, Vaupel JW. Ageing populations: the challenges ahead. Lancet. 2009;374:1196-1208. 
10. World Health Organization. World Health Statistics 2014. Available from: http://www.who.int/mediacentre/news/releases/2014/worldhealth-statistics-2014/en/. Accessed December 15, 2014.

11. Population Reference Bureau. Available from: http://www.prb.org/ DataFinder/Geography/Data.aspx?loc=246. Accessed December 17, 2014.

12. Department of Economic and Social Affairs, United Nations. World population prospects: the 2010 Revision. New York 2011. Available from: http://esa.un.org/unpd/wpp/documentation/pdf/wpp2010 volume-i_comprehensive-tables.pdf. Accessed December 15, 2014.

13. Marengoni A, Angleman S, Melis R, et al. Aging with multimorbidity: a systematic review of the literature. Ageing Res Rev. 2011;10: 430-439.

14. Rechel B, Grundy E, Robine JM, et al. Ageing in the European Union. Lancet. 2013;381:1312-1322.

15. Rosenthal TC, Williams ME, Naughton BJ, editors. Office Care Geriatrics. 6th ed. Philadelphia, PA, USA: Lippincott Williams \& Wilkins; 2006.

16. Cherniack EP, Florez HJ, Troen BR. Emerging therapies to treat frailty syndrome in the elderly. Altern Med Rev. 2007;12:246-258.

17. Danon-Hersch N, Rodondi N, Spagnoli J, Santos-Eggimann B. Prefrailty and chronic morbidity in the youngest old: an insight from the Lausanne cohort Lc65+. J Am Geriatr Soc. 2012;60:1687-1694.

18. Alexandre Tda S, Corona LP, Nunes DP, Santos JL, Duarte YA, Lebrão ML. Similarities among factors associated with components of frailty in elderly: SABE study. J Aging Health. 2014;26:441-457.

19. Statistics Canada. Living arrangements of seniors. Census. Government of Canada. Available from: http://www12.statcan.ca/censusrecensement/2011/as-sa/98-312-x/98-312-x2011003_4-eng.cfm Accessed December 20, 2014.

20. Rockwood K, Mitnitski A, Song X, Steen B, Skoog I. Long-term risks of death and institutionalization of elderly people in relation to deficit accumulation at age 70. J Am Geriatr Soc. 2006;54:975-979.

21. Berk ML, Monheit AC. The concentration of health care expenditures, revisited. Health Aff (Millwood). 2001;20:9-18.

22. US Census Bureau, 65+ in the United States, 2010. P23-212. Washington, DC, USA: US Government Printing Office; 2014. Available from: http://www.census.gov/content/dam/Census/library/ publications/2014/demo/p23-212.pdf. Accessed December 20, 2014.

23. Lassman D, Hartman M, Washington B, Andrews K, Catlin A. US health spending trends by age and gender: selected years 2002-2010. Health Aff (Millwood). 2014;33:815-822.

24. Tomita MR, Russ LS, Sridhar R, Naughton BJ. Smart home with healthcare technologies for community-dwelling older adults. In: Al-Qutayr MA, editor. Smart Home Systems. InTech, 2010. Available from: http:// www.intechopen.com/books/smart-home-systems/smart-homewith-healthcare-technologies-for-community-dwelling-older-adults. Accessed March 31, 2015.

25. Turner KJ, McGee-Lennon MR. Advances in telecare over the past 10 years. Smart Homecare Technology and TeleHealth. 2013;1: 21-34.

26. GPS Life. Ill people remote localization system. Available from: http:// www.gpslife.pl/en/home-page. Accessed December 26, 2014.

27. Tynetec. Telecare. Available from: http://www.tynetec.co.uk. Accessed December 29, 2014.

28. Zagier AS. High-tech sensors help seniors live independently, Fox News, January 23, 2009. Available from: http://www.foxnews.com/ printer_friendly_wires/2009Jan23/0,4675,HighTechSeniorLiving,00. html. Accessed December 26, 2014.

29. Mazzanti I, Maolo A, Antonicelli R. E-Health and telemedicine in the elderly: state of the art. In: Gulla V, Rossi Mori A, editors. Telehealth Networks for Hospital Services: New Methodologies. Hershey, PA, USA: IGI Global; 2013.

30. Takahashi PY, Chandra A, North F, Pecina JL, Upatising B, Hanson GJ. Telemedicine: an enhanced emergency care program for older adults. Smart Homecare Technology and TeleHealth. 2014;2: $55-62$.
31. Takahashi PY, Hanson GJ, Pecina JL, et al. A randomized controlled trial of telemonitoring in older adults with multiple chronic conditions: the Tele-ERA study. BMC Health Serv Res. 2010;10:255.

32. Smith AC, Bensink M, Armfield N, Stillman J, Caffery L. Telemedicine and rural health care applications. J Postgrad Med. 2005;51:286-293.

33. Rosenthal TC, Fox C. Access to health care for the rural elderly. JAMA 2000;284:2034-2036.

34. Tunstall. Monitoring. Available from: http://www.tunstall.co.uk. Accessed December 29, 2014.

35. MATCH Home Care Technologies. Mobilising advanced technologies for care at home: developing home care systems to support independent living. Available from: http://www.match-project.org.uk/main/main. html. Accessed December 29, 2014.

36. SOPHIA Consortium. The SOPHIA service in Germany. Available from: http://www.sophia-franken.de. Accessed December 29, 2014.

37. DALLAS. Delivering Assisted Living Lifestyles at Scale. Available from: https://connect.innovateuk.org/web/dallas/overview. Accessed December 30, 2014

38. Darkins A, Ryan P, Kobb R, et al. Care coordination/home telehealth: the systematic implementation of health informatics, home telehealth, and disease management to support the care of veteran patients with chronic conditions. Telemed J E Health. 2008;14:1118-1126.

39. Fujimoto M, Miyazaki K, von Tunzelmann N. Complex systems in technology and policy: telemedicine and telecare in Japan. Telemed Telecare. 2009;15:175-181.

40. Riken. Bio-mimetic Control Research Center. RI-MAN partner robot. Available from: http://rtc.nagoya.riken.jp/RI-MAN/index_us.html. Accessed December 29, 2014.

41. Parè G, Jaana M, Sicotte C. Systematic review of home telemonitoring for chronic diseases: the evidence base. J Am Med Inform Assoc. 2007; 14:269-277.

42. Clark ML, Gropen T. Advances in the stroke system of care. Curr Treat Options Cardiovasc Med. 2015;17:355.

43. Noel HC, Vogel DC, Erdos JJ, Cornwall D, Levin F. Home telehealth reduces healthcare costs. Telemed J E Health. 2004;10:170-183.

44. Finkelstein SM, Speedie SM, Potthoff S. Home telehealth improves clinical outcomes at lower cost for home healthcare. Telemed JE Health. 2006;12:128-136.

45. Sengpiel J, Fuehner T, Kugler C, et al. Use of telehealth technology for home spirometry after lung transplantation: a randomized controlled trial. Prog Transplant. 2010;20:310-317.

46. Dar O, Riley J, Chapman C. A randomized trial of home telemonitoring in a typical elderly heart failure in North West London: results of the Home-HF study. Eur J Heart Fail. 2009;11:319-325.

47. Prato SD, Nicolucci A, Lovagnini-Scher AC, Turco S, Leotta S, Vespasiani G. Telecare provides comparable efficacy to conventional self-monitored blood glucose in patients with type 2 diabetes titrating one injection of insulin glulisine - the ELEONOR study. Diabetes Technol Ther. 2012;14:175-182.

48. Trief PM, Teresi JA, Eimicke JP, Shea S, Weinstock RS. Improvement in diabetes self-efficacy and glycemic control using telemedicine in a sample of older, ethnically diverse individuals who have diabetes: the IDEATel project. Age Ageing. 2009;38:219-225.

49. Jaana M, Parè G. Home telemonitoring of patients with diabetes: a systematic assessment of observed effects. J Eval Clin Pract. 2007;13: 242-253.

50. Verhoeven F, van Gemert-Pijnen L, Dijkstra K, Nijland N, Seyde E, Steehouder M. The contribution of teleconsultation and videoconferencing to diabetes care: a systematic literature review. J Med Internet Res. 2007;9:e37.

51. Bujnowska-Fedak MM, Puchała E, Steciwko A. The impact of telehome care on health status and quality of life among patients with diabetes in a primary care setting in Poland. Telemed J E Health. 2011;17: $153-160$.

52. Habilis Europe. New concept for rehabilitation. CLEAR Project. Available from: http://www.habiliseurope.eu/. Accessed December 29, 2014. 
53. Faria C, Silva J, Campilho A. Rehab@home: a tool for home-based motor function rehabilitation. Disabil Rehabil Assist Technol. 2015;10: 67-74.

54. Esculier J-F, Vaudrin J, Bériault P, Gagnon K, Tremblay LE. Home-based balance training programme using Wii Fit with balance board for Parkinson's disease: a pilot study. J Rehabil Med. 2012;44:144-150.

55. Sugarman H, Weisel-Eichler A, Burstin A, Brown R. Use of the Wii Fit system for the treatment of balance problems in the elderly: a feasibility study. Presented at the IEEE Virtual Rehabilitation International Conference, Haifa, Israel, June 29 to July 2, 2009.

56. Meldrum D, Glennon A, Herdman S, et al. Virtual reality rehabilitation of balance: assessment of the usability of the Nintendo Wii Fit Plus. Disabil Rehabil Assist Technol. 2012;7:205-210.

57. Making the eHealth connection. MHealth and mobile telemedicine an overview. Available from: http://ehealth-connection.org/content/ mhealth-and-mobile-telemedicine-an-overview. Accessed December 29, 2014.

58. Pew Research Internet Project. Older adults and technology use, April 3, 2004. Available from: http://www.pewinternet.org/2014/04/03/olderadults-and-technology-use/. Accessed January 3, 2015.

59. Rossi MC, Perozzi C, Consorti C, et al. An interactive Diary for Diet Management (DAI): a new telemedicine system able to promote body weight reduction, nutritional education, and consumption of fresh local produce. Diabetes Technol Ther. 2010;12:641-647.

60. Becker S, Mitchell A, Königsmann T, Kribben A, Erbel R. [Mobile applications and management of hypertension: possibilities, problems and perspectives]. Herz. 2012;37:742-745. German.

61. Chou CC, Chang CP, Lee TT, Chou HF, Mills ME. Technology acceptance and quality of life of the elderly in a telecare program. Comput Inform Nurs. 2013;31:335-342.

62. Hirani SP, Beynon M, Cartwright M, et al. The effect of telecare on the quality of life and psychological well-being of elderly recipients of social care over a 12-month period: the Whole Systems Demonstrator cluster randomised trial. Age Ageing. 2014;43:334-341.

63. Bashshur RL, Shannon GW. National telemedicine initiatives: essential to healthcare reform. Telemed J E Health. 2009; 15:600-610.

64. Bujnowska-Fedak MM, Pirogowicz I. Support for e-health services among elderly primary care patients. Telemed J E Health. 2014;20: 696-704.

65. Duplaga M. The acceptance of e-health solutions among patients with chronic respiratory conditions. Telemed J E Health. 2013;19: 683-691.

66. Computer Sciences Corporation. Teleservices for better health: the decade of the non-doctor clinician. Global Institute for Emerging Healthcare Practices. December 2013. Available from: https://assets1. csc.com/health_services/downloads/Teleservices_for_Better_Health_ The_Decade_of_the_Non_Doctor_Clinician.pdf. Accessed March 9, 2015.

67. Ressi M. Today's empowered consumer: the state of digital health in 2011. Manhattan Research 2011. Available from: https://kelley. iu.edu/CBLS/files/conferences/Ressi-Indiana University.pdf. Accessed December 29, 2014.

68. Wentzer HS, Bygholm A. Narratives of empowerment and compliance: Studies of communication in online patients support groups. Int J Med Inform. 2013;82:e386-e394. Available from: http://dx.doi.org/10.1016/j. ijmedinf.2013.01.008. Accessed December 29, 2014.

69. Hanson J, Percival J, Aldred H, Brownsell S, Hawley M. Attitudes to telecare among older people, professional care workers and informal carers: a preventative strategy or crisis management? Univers Access Inf Soc. 2007;6:193-205.

70. Solli H, Hvalvik S, Bjørk IT, Hellesø R. Characteristics of the relationship that develops from nurse-caregiver communication during telecare. J Clin Nurs. February 7, 2015. [Epub ahead of print.]

71. Caregiving in the US. NAC and AARP. National Alliance for Caregiving and AARP, 2009. Available from: http://www.caregiving.org/research/ open-data/. Accessed December 20, 2014.
72. Perlitz U. Tele-medicine improves patient care. Deutsche Bank Research, March 15, 2010. Available from: http://www.dbresearch. com/PROD/DBR_INTERNET_EN-PROD/PROD0000000000255117/ Tele-medicine+improves+patient+care.pdf. Accessed January 7, 2015.

73. Paré G, Sicotte C, St-Jules D, Gauthier R. Cost-minimization analysis of a telehome care program for patients with chronic obstructive pulmonary disease. Telemed J E Health. 2006;12:114-121.

74. Biermann E, Dietrich W, Rihl J, Standl E. Are there time and cost savings by using telemanagement for patients on intensified insulin therapy? A randomised, controlled trial. Comput Methods Programs Biomed. 2002;69:137-146

75. Verhoeven F, van Gemert-Pijnen L, Dijkstra K, et al. The contribution of teleconsultation and videoconferencing to diabetes care: a systematic literature review. J Med Internet Res. 2007;9:e37.

76. Callan A, O'Shea E. Willingness to pay for telecare programmes to support independent living: results from a contingent valuation study. Soc Sci Med. 2015;124:94-102.

77. Palmas W, Shea S, Starren J, et al. Medicare payments, healthcare service use, and telemedicine implementation costs in a randomized trial comparing telemedicine case management with usual care in medically underserved participants with diabetes mellitus (IDEATel). JAMA. 2010;17:196-202.

78. Moreno L, Dale SB, Chen AY, Magee CA. Costs to Medicare of the informatics for diabetes education and telemedicine (IDEATel) home telemedicine demonstration: findings from an independent evaluation. Diabetes Care. 2009;32:1202-1204.

79. Adler R. The age wave meets the technology wave: broadband and Older Americans. SeniorNet 2002. Available from: http://www.seniornet.org/ downloads/broadband.pdf. Accessed March 11, 2015.

80. New Millennium Research Council. Overcoming the psychological barriers to telemedicine: empowering older Americans to use remote health monitoring services. 2007. Available from: http:// newmillenniumresearch.org/archive/Telemedicine_Report_022607. pdf. Accessed March 10, 2015.

81. Organisation for Economic Co-operation and Development. Understanding the brain: the birth of a learning science. Centre for Educational Research and Innovation, 2007. Available from: http:// webarchive.nationalarchives.gov.uk/20130401151715/http://www. education.gov.uk/publications/eOrderingDownload/Understandingthe-brain.pdf. Accessed March 11, 2015.

82. Bujnowska-Fedak MM, Mastalerz-Migas A. Usage of medical internet and e-health services by the elderly. Adv Exp Med Biol. 2015;834: 75-80.

83. Agrell H, Dahlberg S, Jerant AF. Patients' perceptions regarding home telecare. Telemed J E Health. 2000;6:409-415.

84. Zullo N. Depression in elderly care recipients. Guide to long term care planning. National Care Planning Council. Available from: http:/www. longtermcarelink.net/eldercare/depression_elderly_care_recipients. htm. Accessed March 11, 2015.

85. SFGate. Old age in the technology age: New devices to monitor health and well-being at home a growing new sector. San Francisco Chronicle, 2005. Available from: http://www.sfgate.com/business/article/Old-age-in-thetechnology-age-New-devices-to-2617842.php. Accessed March 11, 2015.

86. International Telecommunications Union. The World in 2014. ICT facts and figures. Available from: http://www.itu.int/en/ITU-D/Statistics/ Pages/facts/default.aspx. Accessed January 10, 2015.

87. Mars M. Telemedicine and advances in urban and rural healthcare delivery in Africa. Prog Cardiovasc Dis. 2013;56:326-335.

88. Percival J, Hanson J. Big brother or brave new world? Telecare and its implications for older people's independence and social inclusion. Critical Social Policy. 2006;26:888-909.

89. Clark JS, McGee-Lennon M. A stakeholder centered exploration of the current barriers to the uptake of home care technology in the UK. Assist Technol. 2011;5:12-25. 
90. Pew Internet and American Life Projects. Digital divisions. Available from: http://www.pewinternet.org/files/old-media//Files/Reports/2005/ PIP_Digital_Divisions_Oct_5_2005.pdf.pdf. Accessed March 9, 2015.

91. Takahashi PY, Pecina JL, Upatising B, et al. A randomized controlled trial of telemonitoring in older adults with multiple health issues to prevent hospitalizations and emergency department visits. Arch Intern Med. 2012;172:773-779.

92. Trappenburg J, Groenwold R, Schuurmans M. Increased mortality following telemonitoring in frail elderly patients: look before you leap! Arch Intern Med. 2012;172:1612.

93. Wade R, Cartwright C, Shaw K. Factors relating to home telehealth acceptance and usage compliance. Risk Manag Healthc Policy. 2012;5: $25-33$.
94. Chae YM, Lee JH, Ho SH, Kim HJ, Jun KH, Won JU. Patients' satisfaction with telemedicine in home health services for the elderly. Int $J$ Med Inform. 2001;61:167-173.

95. Tsai CH, Kuo YM, Uei SL. Influences of satisfaction with telecare and family trust in older Taiwanese people. Int J Environ Res Public Health. 2014;11:1359-1368.

96. Rowland D. A five-nation perspective on the elderly. Health Aff (Millwood). 1992;11:205-215.

97. WiserBAN. Smart miniature low power wireless microsystems for body area network. Available from: http://www.wiserban.eu/. Accessed December 31, 2014.

98. Huang JC. Exploring the acceptance of telecare among senior citizens: an application of back-propagation network. Telemed J E Health. 2011;17:111-117.

\section{Publish your work in this journal}

Smart Homecare Technology and TeleHealth is an international, peer-reviewed, open access online journal publishing original research, reviews, editorials and commentaries on the application of technology to support people and patients at home and in assisted living centers to optimize healthcare and management resources. Specific topics in the journal include: Development and application of

\section{Dovepress}

devices within the home and embedded in appliances; Healthcare provider communication and education tools; and drug ordering and adherence. The manuscript management system is completely online and includes a very quick and fair peer-review system, which is all easy to use. Visit http://www.dovepress.com/ testimonials.php to read real quotes from published authors.

Submit your manuscript here: http://www.dovepress.com/smart-homecare-technology-and-telehealth-journal 